\section{Designing Consumer Horticulture Mass Media Programs for Efficiency}

\author{
Diane Relf $f^{1}$, Mary Frank ${ }^{2}$, and Tom Hergert ${ }^{2}$
}

Additional index words. radio, television, newspaper

Summary. An effort has been made to minimize the time involved in production of consumer horticulture radio television, and newspaper columns on a state level, while maximizing quality and utilization. The production of The Virginia Gardener weekly radio program is an annual 4-day marathon ofrecording interviews with subject matter experts. The weekly Virginia Gardener vegetable gardening video series, originally produced for commercial television stations, has been re-issued for cable stations and re-edited for Master Gardener training. The weekly Virginia Gardener newspaper column is written from a computer data bank of press releases prepared in previous years for use by agents in local extension programs.

$\mathrm{S}$ tatewide mass media efforts in radio and television programming provide high visibility for consumer horticulture extension programs; statewide distribution of a weekly newspaper column has been a traditional approach to information distribution by extension media services. Pound (1985) reports that, while people do not seek information of the type provided by the Cooperative Extension Service in newspapers, radio, or television these represent three of the top five places where this information was found by the public in the month preceding the study. Thus, this information reaches an audience that is not seeking the information actively, but is aware that it has been made available, and does pick up considerable information on the topics presented.

Three widely used mass media programs from the Office of Consumer Horticulture at Virginia Tech have been a weekly radio program used on 58 stations a television series used on commercial and cable stations and a column distributed to 110 newspapers. These programs provide high visibility, such as a weekly audience for radio of $>1.6$ million estimated by a survey of the stations using the program. Their educational impact is difficult to determine. however, it is believed to be relatively low in terms of actual behavior change, based on responses to offers ofmaterial or information via radio and press releases. These materials are intended to supplement the efforts of the local extension agents and they provide mass media information to those audiences not currently served by local agents. Methods have been developed to minimize the state extension specialist and stafftime needed to produce these materials and to re-issue materials after minimum modification for use with new audiences.

'Associate Professor. Dept. of Horticulture, Virginia Polytechnic Inst. \& State Univ., Blacksburg, VA 24061-0327,

${ }^{2}$ Producer. Extension Radio/TV Unit, Virginia Polytechnic Inst. \& State Univ., Blacksburg, VA 24061-0327.

\section{Radio}

Through an evolutionary process that started with weekly trips to the Virginia Tech campus radio studios to read a prepared script, the Virginia Gardener radio program has developed into an interview format between the consumer horticulture specialist and appropriate experts from the College of Agriculture at Virginia Tech. Recordings are made of interviews with 12 to 14 experts during a 4-day period in late fall. Each expert is interviewed for five or six 3-min seasonally appropriate programs, and subject matter is selected throughout the year. Prior to the interviews a calendar is developed based on the subjects each guest plans to discuss, and adjustments in topics are made to ensure that five programs are prepared for each month. Programs are timely to the season, but not to the week, as Virginia crosses three climatic zones, with growing seasons ranging from 190 to 290 days. Neither weather conditions nor pest problems are uniform throughout the state due to geographic variations from mountains to beaches.

Each session with an expert requires $\approx 1 \mathrm{~h}$, for a total of 12 to $14 \mathrm{~h}$ of studio tune. In addition to recording time $\approx 4$ four $\mathrm{h}$ are required from the consumer horticulture specialist to make a list oftopics, solicit interviews, and prepare a calendar of programs. The radio producer edits the interviews and produces a finished program on a monthly basis. Her preparation time and the extension specialists' time are reduced annually by a total of $80 \mathrm{~h}$ from previous methods ofprogram recording, which involved writing script outlines and familiarizing the information officer with the subject matter.

There are several additional benefits to this method: having a year's worth of topics completed gives control over production tune in case other major projects arise; portions of the recorded interviews are available for use in other types of radio programming during the year; it assists radio stations in program scheduling, as they receive a full month's program on one tape; and it reduces shipping and handling costs through production and distribution of tapes on a monthly basis.

This is the most widely distributed radio program from the Virginia Cooperative Extension Service, being used on 58 stations and covering $80 \%$ of the geographic regions of the state. Twelve agents incorporate it into their programs and 46 stations use it as a feature. Respondents to a survey of radio stations reported the programs are used an average of twice each week, with au estimated total weekly audience of 1.6 million. It usually is broadcast between 12 noon and $1 \mathrm{pm}$, but several stations use it in the early morning hours.

\section{Television}

The design, production, and distribution of a series of 36 short videotapes (averaging $3.5 \mathrm{~mm}$ ) required 20 staff hours per week ofproduction time for 18 months, including horticulture specialist and video production time.

The availability of the complete program was announced to the three network channels in each of the five viewing areas in the state. Availability was on a first-contact exclusive-usage basis in each of the five viewing areas: Stations in Richmond, Roanoke, and Virginia Beach used the program the first year. One station used the program at 12 noon and $5 \mathrm{pm}$ on Friday, while the other two used it in early morning time slots.

The following year, the program was made available directly to cable television stations and to extension agents for use in their cable programs. The program was used on 12 stations. 
Usage records were not kept the following year, but it is known that at least five of the original stations re-used the program and three other stations used it for the first time. The programs then were re-edited as a set of eight programs running 7 to $10 \mathrm{~min}$ each. Subject matter was grouped into related areas, openings and closing were deleted, and original tapes were edited into the new format. The revised set of programs was re-released through extension agents and cable networks. In addition, this revised set is used as training material for Master Gardeners in 35 localities.

The multiple use of these programs with relatively little editing increases the return on the initial time investment in terms of public exposure. Because the programs cover established cultural practices, the tapes will remain useful and will represent appropriate horticultural practices for many years.

\section{Newspaper}

Some agents contribute weekly garden columns to their local newspapers; however, many of the small local papers in the state do not have extension horticultural information available to them. While some of the 110 newspapers that receive the weekly Virginia Gardener column use it on a regular basis, most of them use it randomly as a filler. It often is converted to a feature article by the newspaper staffrather than being used as a column with a by-line. This use of material is consistent with other types of press releases sent out by the Media Services Dept. at Virginia Tech. While this periodic and unpredictable use does provide visibility to Virginia Tech extension as well as horticultural information for the reader, the amount of time it would require for a specialist to write a unique weekly column does not appear to be justified. Material for these newspaper mailings is prepared monthly by reviewing, editing, and updating information stored in the HORT network on the Virginia Tech mainframe computer. Press releases, prepared and distributed to agents for their exclusive use in local mass media efforts 4 years prior to the current date, are revitalized and re-issued to the newspapers. Total specialist time is $\approx 2 \mathrm{~h} /$ month, with an additional hour of staff time to check the availability of specific plant varieties and similar information. Since all information exists in electronic form, minimal time is required for the Media Services staff to prepare it for distribution. Although no usage records are maintained by Media Services, we know from a clipping service that, during the first 6 months of availability, the column was used regularly by an estimated $13 \%$ of the newspapers, with others using it sporadically.

The production of mass media programs using methods that minimize staff time and use existing resources can provide horticultural information to a wide audience and maintain extensionvisibility among the residential population, while holding down costs. The increasing demands on personnel and the decreasing funds for extension activities make this type of efficient, high-impact production essential to the continuation of extension mass media programming.

\section{Literature Cited}

Pounds, D. 1985. Putting extension information where people will find it. J. Ext. 23:20-23. 